\title{
Direct Correlation of the Crystal Structure of Proteins with the Maximum Positive and Negative Charge States of Gaseous Protein Ions Produced by Electrospray Ionization
}

\author{
Halan Prakash and Shyamalava Mazumdar \\ Department of Chemical Sciences, Tata Institute of Fundamental Research, Homi Bhabha Road, Colaba, \\ Mumbai, India
}

\begin{abstract}
Electrospray mass spectrometric studies in native folded forms of several proteins in aqueous solution have been performed in the positive and negative ion modes. The mass spectra of the proteins show peaks corresponding to multiple charge states of the gaseous protein ions. The results have been analyzed using the known crystal structures of these proteins. Crystal structure analysis shows that among the surface exposed residues some are involved in hydrogen-bonding or salt-bridge interactions while some are free. The maximum positive charge state of the gaseous protein ions was directly related to the number of free surface exposed basic groups whereas the maximum negative charge state was related to the number of free surface exposed acidic groups of the proteins. The surface exposed basic groups, which are involved in hydrogen bonding, have lower propensity to contribute to the positive charge of the protein. Similarly, the surface exposed acidic groups involved in salt bridges have lower propensity to contribute to the negative charge of the protein. Analysis of the crystal structure to determine the maximum charge state of protein in the electrospray mass spectrum was also used to interpret the reported mass spectra of several proteins. The results show that both the positive and the negative ion mass spectra of the proteins could be interpreted by simple consideration of the crystal structure of the folded proteins. Moreover, unfolding of the protein was shown to increase the positive charge-state because of the availability of larger number of free basic groups at the surface of the unfolded protein. (J Am Soc Mass Spectrom 2005, 16, 1409-1421) (c) 2005 American Society for Mass Spectrometry
\end{abstract}

$\mathrm{E}$ lectrospray ionization mass spectrometry (ESIMS) is recognized as a soft ionization method for the study of gaseous ions of large macromolecules such as proteins and nucleic acids [1, 2]. ESI has been used for determination of weak interactions such as intermolecular hydrogen bonding $[3,4]$, proteinprotein complexation [5-7], enzyme-substrate interactions [8], etc. The typical ESI mass spectrum of a protein shows peaks at different $\mathrm{m} / \mathrm{z}$ values corresponding to multiple charge states of the macromolecule and these peaks are usually used to determine its molecular weight. Extensive mass spectrometric studies on unfolding of proteins have been reported in recent years [9-13]. The observed charge states of the protein in the ESI mass spectrum were shown to depend on the tertiary structure of the protein [12]. The charge-state

Published online July 11, 2005

Address reprint requests to Professor S. Mazumdar, Department of Chemical Sciences, Tata Institute of Fundamental Research, Homi Bhabha Road, Colaba, Mumbai, Maharastra 400 005, India. E-mail: shyamal@tifr.res.in distribution in the ESI-MS of the protein was shown to shift to larger positive charge states and becomes broader exhibiting bimodal distribution [14, 15] on unfolding of the protein in solution [9, 12]. Earlier studies [2] have also shown that information about the protein conformations in solution can be inferred from the charge-state distributions observed in electrospray mass spectra. Moreover, the binding properties determined for the protein-substrate noncovalent complexes by ESI-MS methods were shown comparable with those in the solution [16-24]. Soft landing of mass-selected multiple charged gaseous protein ions into liquids (after the mass spectrometric separation) were recently shown [25] to retain the native structures and even the biological activities of some proteins. These reports thus indicate that many structural and functional properties of the protein in solution may remain conserved in the gas-phase protein ions [26, 27].

Recently, there have been extensive studies [28, 29] on the origin of multiple charge states in the ESI mass spectra of proteins and at least two distinct models have 
been proposed. The charge residue model (or Rayleigh limiting charge theory [RLCT]) based on formation of gaseous protein ions by successive evaporation of the solvent from the droplet with subsequent charge transfer from the surface of the droplet to the protein, has been used by some authors to interpret the maximum charge state of the protein [29-31]. This model assumes that the critical droplet size, defined by the Rayleigh limit of the charged droplet as the spherical radius of the protein and the number of charge states of the protein, was proposed to depend on its molecular weight $[28,32]$. The gas-phase basicity of the protein was used to determine the limiting value of the maximum charge state in certain cases [26, 30, 33-36]. Although this model seems to closely account for the experimental maximum charge states observed in several cases, the method of derivation of the charge state requires detailed calculation of the gas-phase basicity of the residues of the protein.

A comparatively simpler model based on charge neutralization of the residues in a protein (conformationdependent neutralization theory [CDNT]) has been proposed to interpret the main charge state in the ESI mass spectrum of the protein [32,37]. The difference between the basic and acidic residues in the protein sequence was used to determine the predominant charge state in the ESI mass spectrum of a protein. Arginine, lysine, and histidine residues were counted as the basic residues, and aspartic acid and glutamic acid were counted as the acidic residues in the protein sequence to calculate the resultant charge of the protein. However, several proteins have been reported to give positive ion mass spectra although they contain an overall negative charge and vice versa, which the charge neutralization model (CDNT) can not explain [37]. Many proteins show both positive as well as negative ion mass spectra and no model has so far been able to provide any rationale for observation of both the positive and the negative ion mass spectra of the same protein. Thus, it is apparent that simple differences between the basic and acidic residues in the protein sequence or consideration of only the molecular mass of the protein are not sufficient to interpret the observed charge states of a protein. The surface exposed basic or acidic groups could hold the charge in the gas phase as proposed earlier [38]. However, some surface exposed residues may form salt bridges, ion pairs, or hydrogen bonds within the protein, reducing the effective charge density on these residues [3] ${ }^{\circ}$ and ${ }^{9}$ thereby ${ }^{\circ}$ decreasing the charge on the protein. Thus, a more detailed consideration of the three-dimensional structure of the protein is essential to understand the mass spectrum of the macromolecule.

In view of this, we have identified the free basic and acidic groups on the protein surface from the crystal structure of the protein. We investigated the electrospray mass spectra of a series of proteins in the folded states and analyzed the observed charge states in terms of the surface exposed free basic and acidic residues of the protein. The numbers of surface exposed free basic residues or free acidic residues were correlated respectively to the maximum positive or negative charge states of the gaseous protein ions. We have performed ESI-quadrupole ion trap mass spectrometric studies of some proteins in the folded forms in both positive and negative ion modes. The results were interpreted using the known crystal structures of the proteins by considering the number of free basic and acidic residues on the surface of the protein. Moreover, this method of determination of maximum charge state based on crystal structure has been used to interpret the reported results for several other proteins in the positive and negative ion modes. Based on these results, a simple model for observation of multiple charge states of the macromolecules has been proposed. The model has also been used to rationalize observation of positive and negative ion mass spectra of the same protein.

\section{Materials and Methods}

Horse heart cytochrome $c$, horse myoglobin, hen egg lysozyme, and bovine carbonic anhydrase were obtained from Sigma Aldrich Co. (Bangalore, India) and these proteins were purified by gel filtration to remove any salt in the solution before the experiment. Purity of the proteins was also checked by sodium dodecyl sulfate polyacrylamide gel electrophoresis. All experiments were performed in Milli $Q$ water (Millipore India Ltd., Bangalore, India).

Mass spectra were obtained using a Thermo Finnigan LCQ Deca Electrospray quadrupole ion trap mass spectrometer (ThermoElectron Co., Hemel Hempstead, Herts, UK). The flow rate of the protein solution was maintained at $5 \mu \mathrm{L} / \mathrm{min}$. Capillary temperature was maintained at approximately $100{ }^{\circ} \mathrm{C}$ and the capillary voltage was kept at $31 \mathrm{~V}$. The ion-spray voltage was maintained at $4.5 \mathrm{kV}$ and the ion optics was tuned to get the maximum ion count. Small variations in these experimental parameters (e.g., temperature, $100{ }^{\circ} \mathrm{C}$ to approximately $200^{\circ} \mathrm{C}$ ) did not affect the observed mass spectrum of the proteins, which showed a monomodal distribution ${ }^{\circ}$ of $^{\circ}$ the ${ }^{\circ}$ charge $^{\circ}$ state $^{\circ}[39]^{\circ}{ }^{\circ}$ The ${ }^{\circ}$ instrument was separately calibrated both in the normal-mass range $(m / z=0-2000)$ and in the high-mass range $(\mathrm{m} / \mathrm{z}=$ $0-4000$ ). Single ion monitoring of a particular charge state of the protein was also performed to detect and resolve the binding of alkali metal ions forming adducts with the protein.

Circular dichroism (CD) spectra were recorded on a thermostated JASCO J810 Spectropolarimeter (JASCO Corporation, Tokyo, Japan) and UV-visible absorption spectra were taken on a Shimadzu UV-2100 spectrophotometer (Shimadzu Scientific Instruments, Tokyo, Japan). Secondary structure of the protein was determined by using the neural network analysis of the far-UV CD data by the secondary structure determination software from JASCO. 


\section{Analysis of Crystal Structure of the Protein to Identify Free Positive and Negative Charges}

The basic residues such as lysine, arginine, and histidine are known to get protonated to form positive charges ${ }^{\circ}$ in $^{\circ}$ the ${ }^{\circ}$ gas $^{\circ}$ phase $^{\circ}[37] .{ }^{\circ}$ Analogously, ${ }^{\circ}$ the ${ }^{\circ}$ acidic residues such as aspartic acid and glutamic acid would contribute to the negative charge of the protein by deprotonation ${ }^{\circ}$ of $^{\circ}$ the ${ }^{\circ}$ acidic ${ }^{\circ}$ groups $^{\circ}[37] .{ }^{\circ}$ Only ${ }^{\circ}$ the ${ }^{\circ}$ residues that are exposed to the surface, contribute to the charge state of the protein and not those buried inside the protein matrix. The surface exposed basic and acidic residues can be identified from the crystal structure of the protein. The crystal structures of the proteins were obtained from Research Collaboratory for Structural Bioinformatics (http://pdbbeta.rcsb.org/pdb/) and ${ }^{\circ}$ analyzed $^{\circ}$ using $^{\circ}$ the $^{\circ}$ WHATIF $^{\circ}$ Server $^{\circ}$ software $^{\circ}\left[40,{ }^{\circ} 41\right]$ (http://swift.cmbi.kun.nl/WIWWWI/).

Close inspection of the crystal structures shows that there are several oppositely charged residues lying close to each other in the folded structure of the proteins. This leads to the possibility of the existence of interaction between some acidic and basic groups of two amino acids of the protein. Formation of ion pairs or existence of salt-bridge interactions involving basic or acidic residues can affect the formal charge of these residues. This would have a direct impact on the net charge and hence the mass spectrum of the protein.

To estimate the number of basic residues that might be involved in the charge interactions, we identified the hydrogen bonds involving the surface exposed basic residues of the protein from the crystal structure. The WHATIF software calculates the optimal hydrogen bonds by using a "force field" determined from a large number of standard hydrogen bonds to describe the hydrogen bond interaction energy. The hydrogen bond distance as well as the angle between the donor and the acceptor were calculated. The calculation of the hydrogen bonded basic residues includes all of the residues in the crystal structure of the protein that have direct interaction with acidic groups and also consider the possible charge delocalization due to interaction of the protonated amine groups (of the basic residues) with partially charged groups such as amide oxygen. These interactions can potentially decrease the effective basicity of the residue and thus decrease its propensity to contribute to the positive charge state of the protein [42].$^{\circ} \mathrm{In}^{\circ}$ general, ${ }^{\circ}$ the ${ }^{\circ}$ gas-phase ${ }^{\circ}$ basicity $^{\circ}$ of ${ }^{\circ}$ arginine ${ }^{\circ}$ is significantly larger compared with that of lysine and histidine, because arginine can participate in different types of noncovalent interactions involving the terminal basic group that are not possible with other basic amino acids. The actual gas-phase basicity of the residue would, however, depend on the nature and number of interactions involving that residue under the constraints of the three-dimensional structure of the pro-

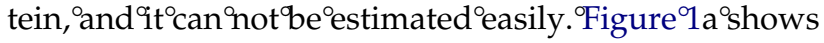
some typical interactions that might affect the basicity or acidity of the residue. It is also important to consider the surface exposed N-terminal amine, which can be protonated to give a positive charge of the protein. The typical surface exposed free basic groups that could contribute to the charge state are also shown in Figure $^{\circ} 1$ a.

The possible salt bridges between the negatively charged groups (carboxylate) and positively charged groups (protonated amines) were identified from the crystal structure of the protein. The residues involved in salt bridges have less acidity compared with an isolated carboxylate group exposed to the surface. A salt bridge with a distance of less than $5 \AA$ recently has been shown to be strong enough to contribute to the stabilization of the ${ }^{\circ}$ protein ${ }^{\circ}[42] .{ }^{\circ}$ Thus, ${ }^{\circ}$ the ${ }^{\circ}$ acidic ${ }^{\circ}$ residues $^{\circ}$ involved ${ }^{\circ}$ in such salt-bridge formation would not contribute to the negative charge of the folded protein. The surface exposed C-terminal carboxylate will contribute a negative charge of the protein. Typical surface exposed free groups that may contribute to the negative charge state

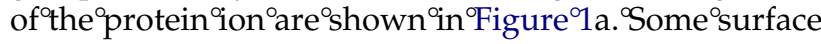
exposed free basic residues and some of those that are in close interaction with each other in the case of cytochrome ${ }^{\circ} \mathrm{C}$ are ${ }^{\circ}$ shown ${ }^{\circ}$ in ${ }^{\circ}$ Figure ${ }^{\circ} 1 \mathrm{~b}$.

The effective charge of the protein would depend on the residues that are free from the salt-bridge or hydrogen-bonding interactions. The maximum possible charge of the protein ion detected in the positive ion mode would thus be given by the sum of the number of free basic residues, the N-terminal amine, and any free charge due to surface exposed metal center (as in case of cytochrome $c$ ). The distribution of the multiple charge states of the protein in the positive ion mass spectrum will depend on the actual basicity of the free basic residues, which is a measure of the propensity of protonation $^{\circ}$ of $^{\circ}$ these ${ }^{\circ}$ centers $^{\circ}[30] . .^{\circ}$ Analogously, ${ }^{\circ}$ the maximum possible negative charge of the protein ion would be given by the sum of the number of isolated acidic residues, the $\mathrm{C}$-terminal carboxylate, and any free negative charge due of the presence of surface exposed anionic cofactors in the protein. The distribution of the multiple charge states of the protein in the negative ion mode will depend on actual acidity of the free acidic residues.

\section{Results and Discussion}

\section{Correlation of the Number of Exposed Free Basic Residues with the Maximum ESI Charge State Observed in the Positive Ion Mode}

Cytochrome c. The electrospray mass spectrum of native ${ }^{\circ}$ cytochrome ${ }^{\circ} \mathrm{C}$ in ${ }^{\circ}$ water ${ }^{\circ}$ is $^{\circ}$ shown in ${ }^{\circ}$ Figure $2 a(i)$. The most intense charge states of cytochrome $c$ in the positive ion mass spectrum are at +6 to +9 , which agrees ${ }^{\circ}$ with $^{\circ}$ earlier ${ }^{\circ}$ reports $^{\circ}\left[39,{ }^{\circ} 43\right] .{ }^{\circ}$ However, ${ }^{\circ}$ careful analyses of results show that the charge-state distribution in the native cytochrome $c$ ranges from +4 to +13 with the highest charge state of this distribution being very weak (less than $1 \%$ of the most intense peak). A 
(a)

i)<smiles>[R2]NC([R1])[Y]</smiles>

ii)<smiles></smiles>

iii)

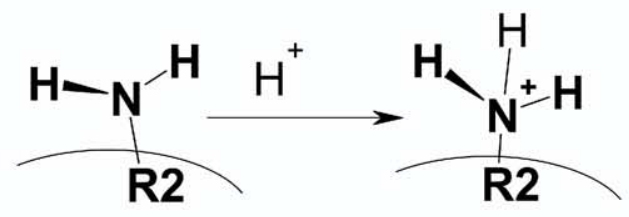

iv)

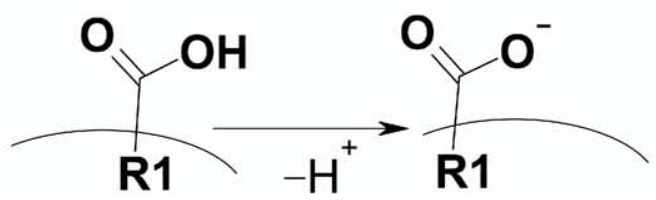

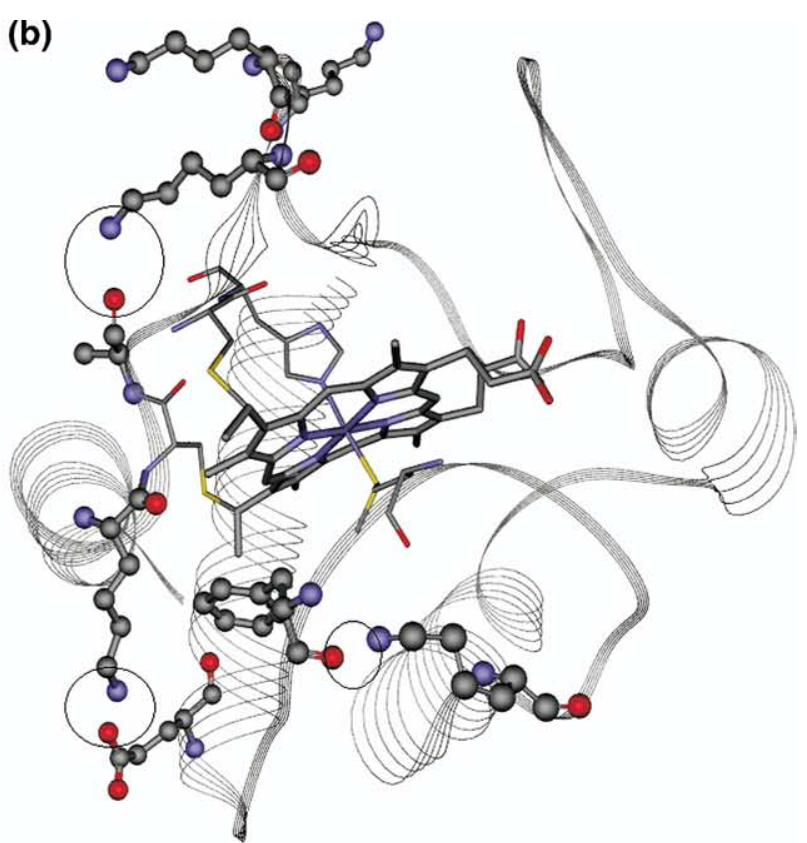

Figure 1. (a) Typical structures of (i) hydrogen-bonded and (ii) salt-bridged residues, (iii) free surface exposed basic residue in neutral and positive-charged form, and (iv) free surface exposed acidic residues in the neutral and charged forms. Dotted curves in (iii) and (iv) represent the surface, and R1 and R2 represent the parts of the amino acids in the protein other than the free basic or acidic groups. (b) Structure of horse cytochrome $c$ (PDB: 1HRC) showing some surface free exposed basic residues. Some closely lying residues at the protein surface involved in hydrogen bonding are marked with circles.

recent'report 939$]^{\circ}$ on ${ }^{9}$ time-of-flight ${ }^{\circ}$ nano-ESI-MS ${ }^{\circ}$ studies of native cytochrome $c$ showed a predominant +9 charge state of the protein in water along with weak peaks corresponding to higher charge states. The charge states show a monomodal distribution as observed earlier ${ }^{\circ}$ for ${ }^{\circ}$ the ${ }^{\circ}$ native ${ }^{\circ}$ proteins ${ }^{\circ}\left[7,{ }^{\circ} 39\right]$. The $^{\circ}$ visible ${ }^{\circ}$ bands in $^{\circ}$ the ${ }^{\circ} \mathrm{CD}^{\circ}$ spectrum ${ }^{\circ}\left(\text { Figure }^{\circ} 3 \mathrm{a}\right)^{\circ}$ of $^{\circ}$ the ${ }^{\circ}$ protein ${ }^{\circ}$ bearing signatures of the tertiary structure around the heme residue $^{\circ}$ also $^{\circ}$ agreed $^{\circ}$ with $^{\circ}$ that $^{\circ}$ reported $^{\circ}$ earlier $^{\circ}[44]$, confirming the existence of the native tertiary structure of the protein in solution. Moreover, the far UV CD spectrum $^{\circ}$ of $^{\circ}$ the $^{\circ}$ protein $^{\circ}$ solution $^{\circ}$ (Figure ${ }^{\circ} 3 a^{\circ}{ }^{\circ}$ inset) confirmed that the protein was in folded conformation with approximately $36 \%$ helicity, which agrees with the crystal $^{\circ}$ structure ${ }^{\circ}$ and ${ }^{\circ}$ matches $^{\circ}$ with $^{\circ}$ earlier ${ }^{\circ}$ reports ${ }^{\circ}[44]$.

To identify the maximum available surface charge of the protein, we analyzed the crystal structure of horse heart cytochrome $c$ (PDB or Protein Data Bank code: 1HRC). The crystal structure shows that all of the 19 lysine residues, 1 of the 2 arginines, and 2 of the 3 histidines, are exposed to the surface in the protein. Close inspection of the foregoing surface exposed charged residues further shows that some of the ex- posed basic residues are involved in an optimal hydrogen-bonding network with some acidic residues or amide carbonyl groups. Moreover, some basic groups are in close (less than $5 \AA$ ) proximity with some acidic groups leading to formation of salt bridges or ion pairs between the residues [42]. Thesegasic'residues thus will have low propensity to contribute to the charge of the protein.

The lysine residues K13, K27, K39, K55, K72, K79, and $\mathrm{K} 99$ are involved in the hydrogen-bonding network or salt-bridge or ion-pair formation. Therefore, among the 19 exposed lysines in the folded cytochrome $c$, only 12 lysine residues would contribute to the charge states in the mass spectrum of the protein. Similar analysis shows that one out of two arginines (R38) and none of the three histidines are exposed to the solvent and thus would not contribute to the charge state in the mass spectrum. The N-terminal glycine is acetylated in the horse cytochrome $c$ (obtained from Sigma); thus, the N-terminal amine possibly does not contribute to the charge state of the protein. The ferric heme group (prosthetic group), on the other hand, would contribute one positive charge of the gaseous protein ion as the 
(a)
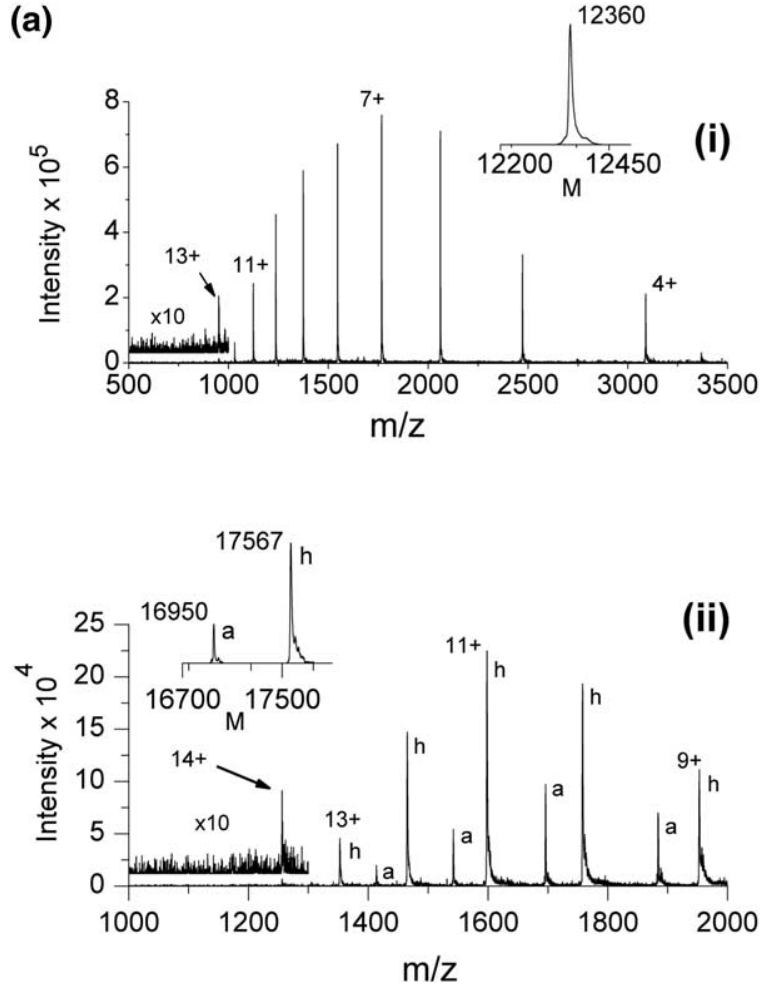

(b)
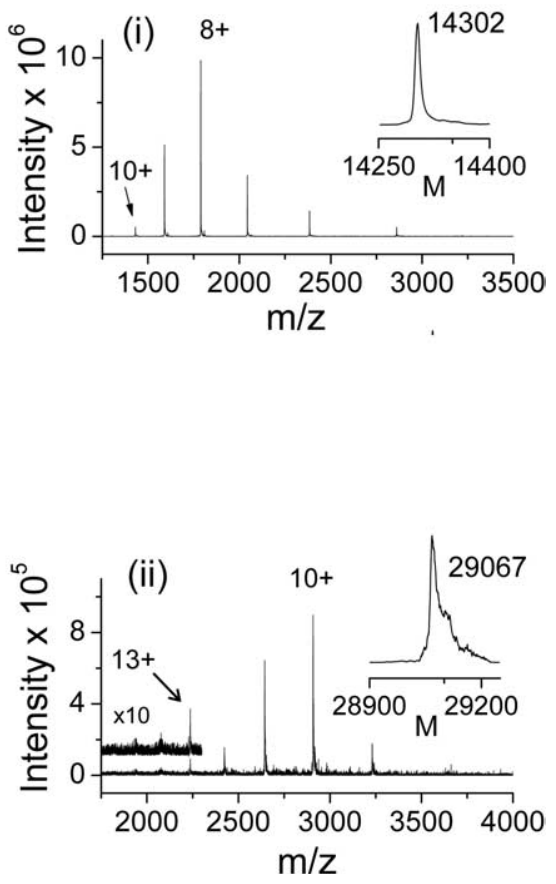

Figure 2. (a) Positive ion ESI mass spectrum of (i) horse cytochrome $c(8 \mu \mathrm{M})$ and (ii) horse myoglobin $(4 \mu \mathrm{M})$. The inset shows the deconvoluted mass of the molecule. (b) Positive ion ESI mass spectrum of (i) hen egg lysozyme $(7 \mu \mathrm{M})$ and (ii) bovine carbonic anhydrase II (5 $\mu \mathrm{M})$. The inset shows the deconvoluted mass of the molecule.

heme is exposed to the surface. Thus, the maximum positive charge state expected from folded cytochrome $c$ is +13 (contributions due to 12 free lysine and 1 heme). The foregoing analysis of the crystal structure of the protein thus supports the observation of a maximum of +13 charge state of the folded cytochrome $c$ in $a^{\circ}$ positive ${ }^{\circ}$ ion $^{\circ} \mathrm{ESI}^{\circ}$ mass $^{\circ}$ spectrum ${ }^{\circ}$ as $^{\circ}$ shown $^{\circ}$ in ${ }^{\circ}$ Figure 2a(i). ${ }^{\circ}$ Nevertheless, ${ }^{\circ}$ the ${ }^{\circ}$ present ${ }^{\circ}$ analysis ${ }^{\circ}$ puts ${ }^{\circ}$ an ${ }^{\circ}$ upper limit to the maximum observable charge state of the protein in its folded form. The exact number of charge states and the charge-state distribution observed in the folded protein would depend on the actual state of protonation of the 12 free lysines at the surface of the protein. Some of the surface exposed free basic residues and some exposed hydrogen bonded residues of cytochrome ${ }^{\circ} \mathrm{C}$ are ${ }^{\circ}$ shown ${ }^{\circ}{ }^{\circ}$ Figure ${ }^{\circ} 1 b$. The $^{\circ}$ results ${ }^{\circ} f^{\circ}$ chargestate analysis by this method along with those by the

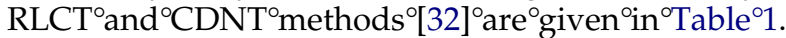

The calculation of the average mass of cytochrome $c$ based on the positive ion spectrum for a protonated molecule [45] ${ }^{\circ}$ of the type $\left[\mathrm{MH}_{n}\right]^{n+}$ (for $n=4-13$ ) shows an average molecular weight of the protein $(\mathrm{M})$ as $12,359^{\circ} \pm{ }^{\circ} 2^{\circ}$ [Figure ${ }^{\circ} 2 \mathrm{a}(\mathrm{i}),{ }^{\circ}$ inset]. ${ }^{\circ}{ }^{\circ}$ This ${ }^{\circ}$ matches $^{\circ}$ with $^{\circ}$ the calculated most abundant isotopic mass (12,359.342 Da) of the protein (with the $\mathrm{N}$-terminal acetylated) obtained from the sequence. This analysis suggests that all of the acidic residues in the positive ions of cytochrome $c$, that is, the aspartic acids, glutamic acids, and the heme propionic acid groups, are in the neutral (protonated) form $^{\circ}$ (Figure $\left.{ }^{\circ} 1 \mathrm{a}\right)$.

Myoglobin. The positive ion ESI mass spectrum of native ${ }^{\circ}$ myoglobin $^{\circ}$ was $^{\circ}$ studied $^{\circ}{ }^{\circ}{ }^{\circ}{ }^{\text {water }}{ }^{\circ}\left[\right.$ Figure $\left.^{\circ} 2 a(i i)\right]$. The charge states of myoglobin from +9 to +14 were observed in the mass spectrum of the protein with concomitant appearance of the peaks of the apoprotein at the same charge states, which agrees with earlier reports ${ }^{\circ}\left[13,{ }^{\circ} 24,46,{ }^{\circ} 47\right]^{\circ}$ The $^{\circ}$ intensity ${ }^{\circ}$ of $^{\circ}$ the ${ }^{\circ}+14^{\circ}$ charge state is less than $5 \%$ of the maximum intensity peak and has ${ }^{\circ}$ not $^{\circ}$ been ${ }^{\circ}$ clearly ${ }^{\circ}$ identified $[13,24,46,47]$. The ${ }^{\circ}$ mass spectral signals of myoglobin were about one order of magnitude weaker compared with the signals of cytochrome $c$. The far-UV and visible $C D$ spectra of the aqueous ${ }^{\circ}$ myoglobin ${ }^{\circ}$ solution $^{\circ}\left(\text { Figure }^{\circ} 3 \mathrm{~b}\right)^{\circ}$ confirmed $^{\circ}$ that the protein was in folded conformation with approximately $70 \%$ helicity, which agreed with the crystal structure ${ }^{\circ}$ and $^{\circ}$ matched $^{\circ}$ with $^{\circ}$ earlier ${ }^{\circ}$ reports ${ }^{\circ}[15]$.

Analysis of the crystal structure of horse myoglobin (PDB code: 1WLA) was performed to determine the maximum possible charge states in the mass spectrum of the folded protein. All of the 19 lysine residues of horse myoglobin are exposed to the solvent but 11 of them are involved in hydrogen-bond or salt-bridge formation in the crystal structure of the protein. The remaining 8 lysine residues (K16, K45, K62, K63, K77, $\mathrm{K} 87, \mathrm{~K} 96$, and K147) at the protein surface are free and 

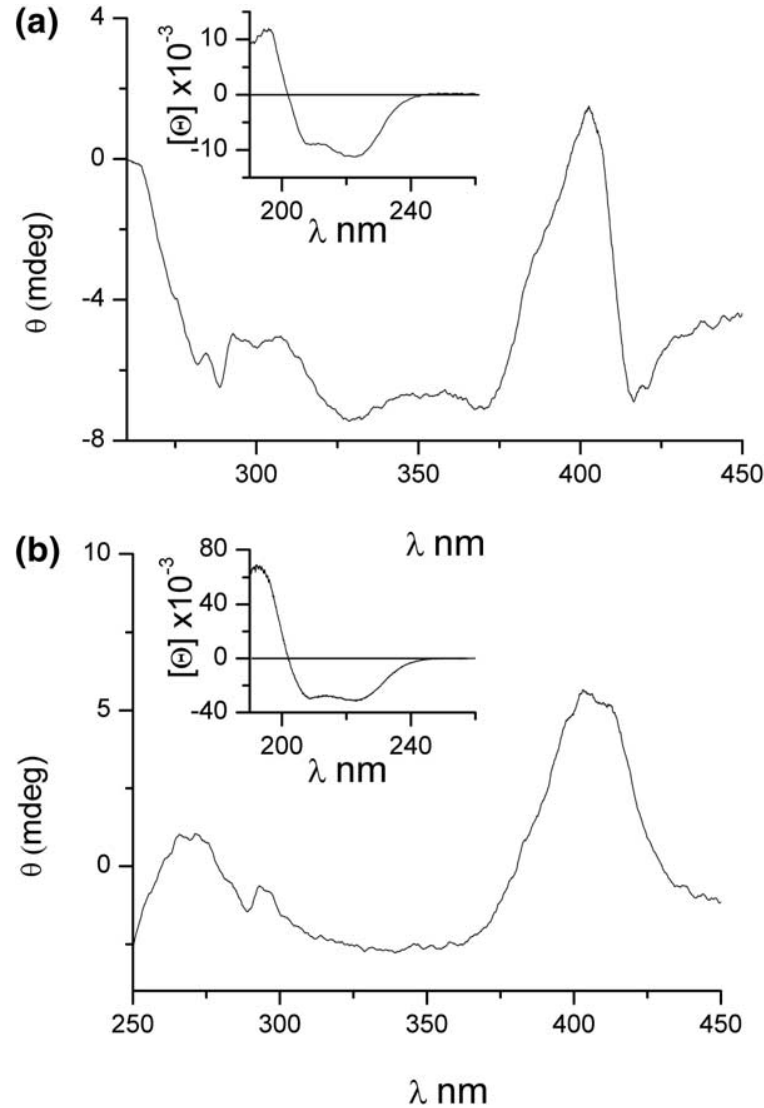

Figure 3. CD spectra of (a) cytochrome $c$ and (b) myoglobin in the visible region. Insets show the corresponding far-UV CD spectra of the proteins, where $[\Theta]\left(\mathrm{deg} . \mathrm{cm}^{2} / \mathrm{dmol}\right)$ is per residue molar ellipticity. Concentration of the protein was approximately $20 \mu \mathrm{M}$ and the path length for visible spectral studies was $10 \mathrm{~mm}$ and for the far-UV CD the path length for visible spectral studies was $1 \mathrm{~mm}$.

therefore can contribute to the charge state. Out of two arginine residues only one (R31) is free to contribute to the charge at the surface of the protein. On the other hand, out of 11 histidines, 6 residues are exposed to the surface of myoglobin and among them 3 residues are involved in hydrogen-bonding or salt-bridge formation, and the remaining 3 histidines ( $\mathrm{H} 36, \mathrm{H} 81$, and $\mathrm{H} 113$ ) would contribute to the positive charge state of the protein. Thus, the analysis of the crystal structure of myoglobin suggests that there could be a maximum of 14 positive charges (8 lysine, 1 arginine, 3 histidine, the $\mathrm{N}$-terminal amine, and 1 positive charge due to ferric heme) possible for the folded myoglobin. This result agrees with our experimental observations and supports that the surface exposed free basic residues are the only sites responsible for the positive charge state in the folded protein. The results of charge-state analysis by this method along with those by the RLCT and CDNT methods ${ }^{\circ}[32]^{\circ}$ are $^{\circ}$ given ${ }^{\circ}{ }^{\circ}{ }^{\circ}$ Table $^{\circ} 1$.

The calculation of average mass of myoglobin based on the positive ion spectrum for the neutral molecule $[45]^{\circ}$ shows $^{\circ}$ an $^{\circ}$ average $^{\circ}$ molecular $^{\circ}$ weight $^{\circ}$ of $^{\circ} 17,567^{\circ} \pm{ }^{\circ} 5$ [Figure ${ }^{\circ} 2 a(i i),{ }^{\circ}$ inset,$^{\circ}{ }^{\circ}$ which ${ }^{\circ}$ closely $^{\circ}$ matches $^{\circ}{ }^{\circ}$ with ${ }^{\circ}$ the calculated most abundant isotopic mass $(17,567.76 \mathrm{Da})$ of the holoprotein obtained from the sequence. Analogous to cytochrome $c$, the positive ion spectrum of myoglobin also thus supports that the positive charge of the protein ion arises due to the free basic residues on its surface.

Lysozyme. The chicken egg lysozyme has been extensively ${ }^{\circ}$ studied ${ }^{\circ}$ by $^{\circ}$ ESI-MS $\left[26,32,{ }^{\circ} 37\right] .{ }^{\circ}$ The ${ }^{\circ}$ crystal $^{\circ}$ structure (PDB code: 1DPX) shows that all of the basic residues in lysozyme (6 lysines, 11 arginines, and 1 histidine) are exposed to the solvent. However, identification of possible hydrogen bonds of the basic sites with one or more acidic centers shows that not all of the exposed basic residues can contribute to the positive charge state of the protein. Only two lysines (K13 and K97), six arginines (R14, R21, R73, R112, R114, and $\mathrm{R} 128$ ), and the histidine (H15) are free and can give rise to the charge state of the protein ion. Thus, the maximum charge state for this protein identified by this method is +10 (2 lysine, 6 arginine, 1 histidine, and the $\mathrm{N}$-terminal residue). ESI mass spectrum of folded lysozyme in aqueous solution (disulfide-intact) given in Figure $^{\circ} 2 \mathrm{~b}(\mathrm{i})^{\circ}$ shows $^{\circ}+5$ to $+10^{\circ}$ charge $^{\circ}$ states $^{\circ}$ of $^{\circ}$ the protein, ${ }^{\circ}$ which ${ }^{\circ}$ agrees $^{\circ}{ }^{\circ}$ with $^{\circ}$ earlier ${ }^{\circ}$ reports ${ }^{\circ}[26] .^{\circ}$ Recent mass spectral studies on lysozyme in nondenaturing solvent ${ }^{\circ}$ conditions $^{\circ}[48]^{\circ}$ show $^{\circ}$ that ${ }^{\circ}$ the ${ }^{\circ}$ maximum ${ }^{\circ}$ charge state of the protein in ammonia solution is +10 with the most intense peak at +8 . Studies on ion soft landing of the +10 charge state of the protein ions recently were shown ${ }^{\circ}[25]^{\circ}$ to ${ }^{\circ}$ conserve $e^{\circ}$ the ${ }^{\circ}$ polysaccharide ${ }^{\circ}$ degradation activity ${ }^{\circ}$ of $^{\circ}$ enzyme $^{\circ}$ It $^{\circ}$ was $^{\circ}$ also ${ }^{\circ}$ shown $^{\circ}[48]^{\circ}$ that ${ }^{\circ}$ the charge-state distribution depends on the nature of the solvent and less basic solvents promote less ionization of the protein, because the maximum charge state of lysozyme observed in 1,4-tetramethyl butanediamine was only +5 . Unfolding of lysozyme by reduction of its disulfide ${ }^{\circ}$ bonds $^{\circ}$ was $^{\circ}$ shown $^{\circ}[11]^{\circ}$ to ${ }^{\circ}$ increase ${ }^{\circ}$ the ${ }^{\circ}$ maximum charge state from +10 to +21 . The results thus support that the possible maximum charge state of folded lysozyme is +10 and the exact observation of the charge-state distribution would depend on the solvent properties and exact basicities of the isolated basic residues at the protein surface. Moreover, unfolding of the protein would break some of the hydrogen bonds involving the basic residues and show higher positive charge states in the mass spectrum of the unfolded protein. The results of charge-state analysis by this method along with those by the RLCT and CDNT methods [32] are ${ }^{\circ}$ given in Table 1 . The ${ }^{\text {molecular }}{ }^{\circ}$ weight calculated ${ }^{\circ}$ from $^{\circ}$ the ${ }^{\circ}$ reported $^{\circ}[48]^{\circ}$ charge $^{\circ}$ states $^{\circ}$ of ${ }^{\circ} l y-$ sozyme $^{\circ}$ is ${ }^{\circ} 14,302^{\circ} \pm^{\circ} 2^{\circ} \mathrm{Da}^{\circ}$ (Figure ${ }^{\circ} 2 \mathrm{~b}(\mathrm{i}),{ }^{\circ}$ inset), ${ }^{\circ}$ which ${ }^{\circ}$ is close to that for the sequence obtained in the crystal structure $(14,296 \mathrm{Da})$ with the first 18 residues depleted from the unprocessed sequence given in SwissProt database (LYC_CHICK). The calculated molecular weight from the unprocessed enzyme (SwissProt ID: LYC_CHICK) is $16,238 \mathrm{Da}$. This further justifies the use 
Table 1. Charge states of gaseous protein ions in ESI

\begin{tabular}{|c|c|c|c|c|c|c|c|c|c|c|}
\hline \multirow[b]{2}{*}{$\begin{array}{l}\text { Protein (PDB code) } \\
+ \text { ve/-ve ion spectra }\end{array}$} & \multirow[b]{2}{*}{ MW } & \multirow[b]{2}{*}{$\begin{array}{l}\mathrm{BR} \\
(\mathrm{AR})\end{array}$} & \multicolumn{2}{|c|}{ MIC } & \multicolumn{2}{|c|}{$\mathrm{MC}$} & \multirow[b]{2}{*}{$\begin{array}{l}\text { SEBR } \\
\text { (SEAR) }\end{array}$} & \multirow[b]{2}{*}{$\begin{array}{l}\text { SEFBR } \\
\text { (SEFAR) }\end{array}$} & \multirow[b]{2}{*}{$\mathrm{MC}_{\text {cal }}$} & \multirow[b]{2}{*}{ Ref. } \\
\hline & & & CDNT & $\mathrm{MIC}_{\mathrm{Obs}}$ & RLCT & $\mathrm{MC}_{\mathrm{Obs}}$ & & & & \\
\hline Ubiquitin (1UBQ) + ve & 8547 & $12(11)$ & +1 & +6 & +7 & +8 & 11 & 4 & +5 & 32 \\
\hline Acyl CoA (1HB6) + ve & 9869 & $18(17)$ & +1 & +8 & +7 & +10 & 16 & 9 & $+10^{*}$ & 53 \\
\hline $\begin{array}{l}\text { SrcSH2 Domain (1SPR) } \\
\quad+\text { ve }\end{array}$ & 11935 & $18(22)$ & -5 & +7 & +8 & +8 & 17 & 8 & +9 & 54 \\
\hline $\begin{array}{l}\text { Trp repressor (2WRP) } \\
\quad+\text { ve }\end{array}$ & 12207 & $15(16)$ & -1 & +7 & +9 & $+15^{\mathrm{a}}$ & 15 & 11 & +12 & 55 \\
\hline Cytochrome $c$ (1HRC) & & & +12 & +7 & +9 & +13 & 22 & 12 & $+13^{b, c}$ & This work \\
\hline $\begin{array}{l}\text { +ve } \\
\text { Cytochrome } c(1 \mathrm{HRC}) \\
\quad \text {-ve }\end{array}$ & 12360 & $24(12)$ & +12 & -5 & -9 & -5 & (11) & (4) & $-7^{d}$ & This work \\
\hline RNase $A(1 R O B)+$ ve & 13674 & $18(10)$ & +8 & +7 & +9 & +7 & 15 & 8 & +9 & 17 \\
\hline RNase $A(1 R O B)-v e$ & & & +8 & -6 & -9 & -7 & (7) & (6) & -7 & 47 \\
\hline $\begin{array}{l}\alpha \text {-Lactalbumin (1F6S) } \\
\quad+\text { ve }\end{array}$ & 14169 & $16(20)$ & -4 & +8 & +9 & +11 & 15 & 11 & +12 & 49 \\
\hline Lysozyme (1DPX) + ve & 14302 & $18(9)$ & +9 & +8 & +9 & +10 & 18 & 9 & +10 & This work \\
\hline Lysozyme (1DPX) - ve & & & +9 & -6 & -9 & -6 & (7) & (5) & -6 & 11 \\
\hline $\begin{array}{l}\text { Chorismate Mutase } \\
\qquad(1 \mathrm{DBF})+\text { ve }\end{array}$ & 14472 & $19(19)$ & 0 & +5 & +9 & +10 & 16 & 10 & +11 & 18 \\
\hline $\begin{array}{l}\text { Myoglobin (1WLA) } \\
+ \text { ve }\end{array}$ & 17567 & $32(21)$ & +11 & +11 & +10 & +14 & 27 & 12 & $+14^{\mathrm{e}}$ & This work \\
\hline $\begin{array}{l}\text { Myoglobin (1WLA) } \\
\text {-ve }\end{array}$ & & & +11 & -6 & -10 & -6 & (20) & (4) & $-7^{d}$ & This work \\
\hline $\begin{array}{l}\beta \text {-Lactaglobulin (1B8E) } \\
\quad+\text { ve }\end{array}$ & 18265 & $19(14)$ & +5 & +8 & +10 & +11 & 18 & 12 & +13 & 56 \\
\hline $\begin{array}{l}\text { Inorganic } \\
\text { pyrophosphatase } \\
(1 \mathrm{IGP})+\text { ve }\end{array}$ & 19544 & $25(29)$ & -4 & +9 & +11 & +14 & 21 & 14 & +15 & 24 \\
\hline $\begin{array}{l}\text { Bovine carbonic } \\
\text { anhydrase (1V9E) } \\
+ \text { ve }\end{array}$ & 29067 & $38(30)$ & +9 & $+15,+14$ & +13 & +13 & 29 & 16 & $+17^{f}$ & This work \\
\hline $\begin{array}{l}\text { Human carbonic } \\
\text { anhydrase II (2CBA) } \\
\text { +ve }\end{array}$ & 29180 & $43(32)$ & +11 & +11 & +13 & +12 & 36 & 14 & $+14^{b, f}$ & 28 \\
\hline $\begin{array}{l}\text { Human serum } \\
\text { transferrin (1BP5) } \\
\text { +ve }\end{array}$ & 37153 & $48(39)$ & +9 & +13 & +15 & +15 & 41 & 15 & +16 & 57 \\
\hline
\end{tabular}

*The cadmium ion attached to His14 in 1HB6 may contribute two more positive charges i.e., MCcal $=+12$.

Trp- repressor spectrum taken at $\mathrm{pH}$ 6, shows bimodal distribution and might have partially unfolded species.

bThe N-terminal residue acetylated hence do not contribute to positive charge.

${ }^{c}$ Ferric heme contributed one positive charge.

${ }^{\mathrm{d}} \mathrm{C}$-terminal residue and two heme propionates contribute to the negative charge.

eN-terminal amine and ferric heme contribute to the positive charge.

fThe zinc ion is buried inside the protein core and the charge of the metal ion is possibly neutralized by surrounding protein environment.

Key: BR, total no. basic residues; AR, total no. acidic residues, shown in parentheses; MIC, most intense charge; MC, maximum charge; SEBR, exposed basic residue; SEAR, exposed acidic residue, shown in parentheses; SEFBR, esposed free basic residue; SEFAR, exposed free acidic residue, shown in parentheses; MCcal, calculated maximum charge state; CDNT, conformation-dependent neutralization theorymodel; RLCT, Rayleigh limiting charge theory.

of the crystallographic sequence and structure for the analysis of the mass spectrum of this protein.

Bovine carbonic anhydrase II. The bovine carbonic anhydrase II is a zinc containing enzyme. The ESI mass spectrum of the enzyme at ambient $\mathrm{pH}$ in the folded conformation ${ }^{\circ}$ is $^{\circ}$ shown $^{\circ}$ in $^{\circ}$ Figure $^{\circ} 2 \mathrm{~b}$ (ii)..$^{\circ}$ The $^{\circ}$ maximum charge state of +13 [with very weak signals up to $15+$,

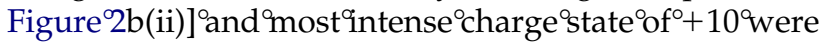
observed in the mass spectrum of the folded bovine carbonic anhydrase II.

Analysis of the crystal structure (PDB code: 2CBA) of the enzyme was used to identify the maximum charge state possible for the folded enzyme. The crystal structure shows that all of the 18 lysine residues of the enzyme are exposed to the surface, whereas 6 of nine arginines, and 5 of 11 histidines are surface exposed. There are 6 lysine residues involved in hydrogen bonding, thus leaving 12 lysine residues (K8, K17, K35, K44, K79, K111, K112, K147, K157, K170, K223, and K259) free to contribute to the charge state of the protein. Analogously, two histidine residues (H3 and H9) and two arginines (R56 and R110) are available to contribute to the charge state of the protein. Thus, the total expected charge state of carbonic anhydrase is +17 (12 lysine, 2 histidine, 2 arginine, and the N-terminal 
amine). The $\mathrm{Zn}^{2+}$ ion is coordinated through $\mathrm{H} 93, \mathrm{H} 95$, H118 (all buried), and water that is also buried inside the protein. Thus, the $\mathrm{Zn}^{2+}$ center possibly does not contribute to the charge state of the protein ion. The experimentally observed maximum charge state agrees with that determined based on the crystal structure of the protein. The molecular weight calculated from the mass spectrum of carbonic anhydrase [shown in inset Figure $2 \mathrm{~b}$ (ii) ] ${ }^{\circ}$ was $29,067^{\circ} \pm 10$, which agrees ${ }^{\circ}$ with that ${ }^{\circ}$ of the enzyme with one zinc ion and water attached to the protein $^{\circ}[49]^{\circ}{ }^{\circ} \mathrm{A}^{\circ}$ decrease ${ }^{\circ}$ in $^{\circ} \mathrm{pH}^{\circ}$ of $^{\circ}$ the ${ }^{\circ}$ solution ${ }^{\circ}$ causes observation of higher charge states in the mass spectrum of the protein, possibly because of unfolding as reported ${ }^{\circ}$ earlier ${ }^{\circ}[49]$.

Human carbonic anhydrase II and other proteins. The human carbonic anhydrase II is analogous to bovine carbonic anhydrase and several authors have reported its $^{\circ}$ electrospray ${ }^{\circ}$ mass $^{\circ}$ spectra $^{\circ}\left[28,{ }^{\circ} 32,{ }^{\circ} 34,{ }^{\circ} 37\right]^{\circ}$, which show multiple charge states up to $a+12$ charge state of the enzyme.

Analysis of the crystal structure (PDB code: 2CBA) of the enzyme shows that all of the 24 lysine residues of the enzyme are exposed to the surface, and 5 of 7 arginines and 7 of 12 histidines are surface exposed. There are 15 lysine residues involved in hydrogen bonding, thus leaving 9 lysine residues (K8, K23, K38, $\mathrm{K} 79$, K110, K112, K223, K226, and K259) free to contribute to the charge state of the protein. Analogously, five histidine residues $(\mathrm{H} 2, \mathrm{H} 9, \mathrm{H} 16, \mathrm{H} 35$, and $\mathrm{H} 63)$ are available to contribute to the charge state of the protein. Thus, the total expected charge state of carbonic anhydrase is +14 (9 lysine and 5 histidine). The $\mathrm{N}$-terminal serine residue in carbonic anhydrase II is acetylated. Analogous to bovine carbonic anhydrase the zinc center coordinated through H93, H95, and H118 (all buried) possibly does not contribute to the charge state of the protein ion. The predicted maximum charge state of human carbonic anhydrase agrees well with that reported ${ }^{\circ}$ earlier $\left[28,{ }^{\circ} 32,{ }^{\circ} 34,37\right]$.

Results of the analyses of the crystal structures to determine possible maximum surface charge of several proteins ${ }^{\circ}$ are ${ }^{\circ}$ given ${ }^{\circ}$ in $^{\circ}$ Table $^{\circ} 1^{\circ}$ along $^{\circ}$ with $^{\circ}$ the ${ }^{\circ}$ observed charge states of the gaseous protein ions in the mass spectra and the charge states estimated by RLCT and CDNT methods. The calculated maximum charge states of $^{\circ}$ the $^{\circ}$ proteins $^{\circ}$ agree $^{\circ}$ well $^{\circ}$ with $^{\circ}$ those $^{\circ}$ observed experimentally.

\section{Unfolding of Cytochrome $\mathrm{c}$ and Myoglobin}

Unfolding of the protein brings buried segments out to the solvent. Thus, the basic residues, which were not accessible to the solvent in the folded form, become exposed to the surface and can give rise to higher charge states in the unfolded protein. Moreover, the surface exposed basic residues, which are involved in hydrogen-bonding or salt-bridge interactions in the folded protein, may also become available to contribute to the charge state of the unfolded protein. Unfolding of proteins thus shows an increase in the maximum charge in the ESI mass spectra. The maximum charge state possible in the totally unfolded protein should equal the total number of basic residues in the sequence.

Thus, the unfolded horse cytochrome $c$ can have a maximum of 24 positive charge states (19 lysine, 2 arginine, 2 of 3 histidines, and the covalently bound heme center). Histidine 18 remains bound to the heme even in the unfolded form of the protein; hence, it is not likely to contribute to the charge state. The N-terminal glycine in cytochrome $c$ (horse heart) is acetylated; hence, it is also not available for protonation. Earlier experimental ${ }^{\circ}$ studies ${ }^{\circ}$ have $[50]^{\circ}{ }^{\circ}{ }^{2}$ ported $^{\circ}{ }^{\circ}{ }^{\circ}$ observation of charge state of up to +24 from unfolded cytochrome $c$ in the presence of $50 \%$ methanol and $3 \%$ acetic acid and $1 \% m$-nitrobenzyl alcohol, which supports our analysis.

Analogously, unfolded horse myoglobin can have a maximum of 33 positive charge states (19 lysine, 2 arginine, 11 histidine, and the N-terminal amine) in the mass spectrum of the protein. The heme in myoglobin is released out of the protein on unfolding and does not contribute to the charge state of the unfolded protein. Earlier $^{\circ}$ reports $^{\circ}\left[15,{ }^{\circ} 51\right]^{\circ}$ on $^{\circ}$ ESI-MS $^{\circ}$ studies ${ }^{\circ}$ of $^{\circ}$ horse myoglobin at acidic solution showed a charge state as high as +26 . The fact that the maximum charge state in the unfolded proteins can be explained on the basis of only the number of basic residues in the protein shows that the observation of the charge state of the protein depends on the number of protonable sites (i.e., basic residues) and not on the difference of the basic and acidic $^{\circ}$ residues $^{\circ}$ as $^{\circ}$ proposed $^{\circ}$ earlier ${ }^{\circ}[37]$.

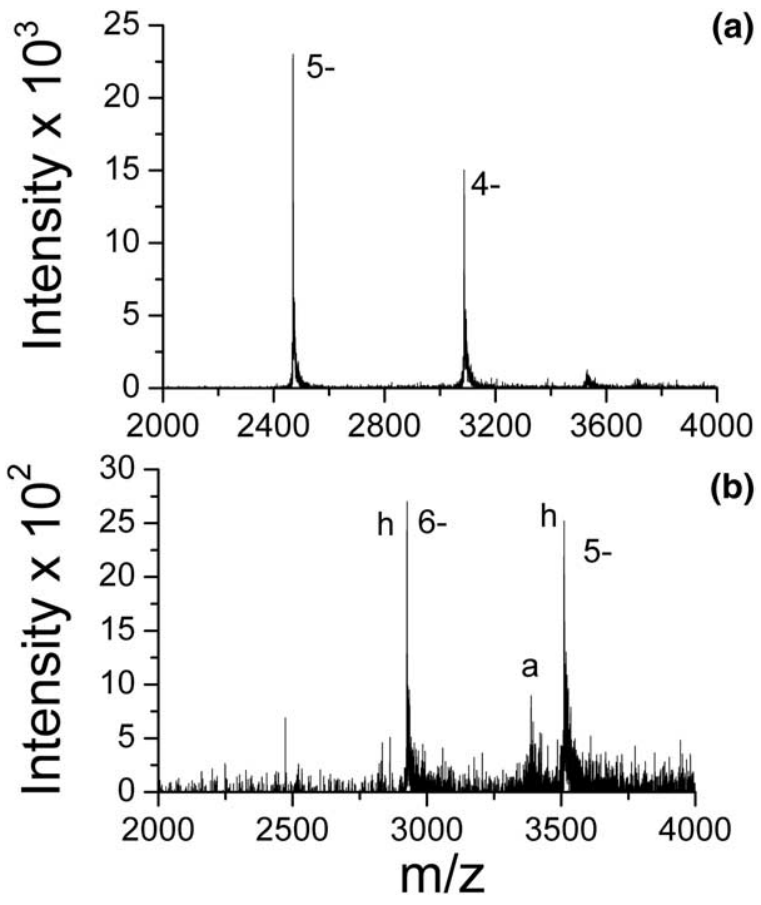

Figure 4. Negative ion ESI mass spectrum of (a) cytochrome $c$ (8 $\mu \mathrm{M})$ and (b) horse myoglobin $(4 \mu \mathrm{M})$. 
Correlation of the Number of Free Acidic Residues with the Maximum ESI Charge State Observed in the Negative Ion Mode

Cytochrome c in negative ion mode. The electrospray mass spectrum of cytochrome $c$ in the negative ion mode $^{\circ}$ is ${ }^{\circ}$ shown $^{\circ}$ in ${ }^{\circ}$ Figure $^{\circ} 4 \mathrm{a}^{\circ}{ }^{\circ}$ The $^{\circ}-4^{\circ}$ and ${ }^{\circ}-5^{\circ}$ charge states of the protein in aqueous solution were observed with the -5 charge state as the most intense peak. Horse cytochrome $c$ (PDB code: 1HRC) consists of nine glutamic acids and three aspartic acids, of which one aspartic acid is buried inside. The two propionic acid side chains of the heme in cytochrome $c$ as well as all the acidic residues in the protein are possibly deprotonated in the negative ion mass spectrum of the protein. Crystal structure analysis of salt bridges in the protein shows that five glutamic acid residues and two aspartic acid residues are involved in salt bridges with some basic groups (lysine or arginine side-chain nitrogens) residing at less than $5 \AA$ from the acidic center. A salt-bridge distance of approximately $5 \AA$ recently has been $^{\circ}$ shown $^{\circ}[42]^{\circ}$ to $^{\circ}$ be $^{\circ}$ sufficient ${ }^{\circ}$ to $^{\circ}$ stabilize ${ }^{\circ}$ the ${ }^{\circ}$ salt bridge and thus the ions involved in such salt-bridge formation would not contribute to the charge state of the protein. Taking this into account, four glutamic acid residues (E4, E21, E62, and E66) at the protein surface contribute to the negative charge of the protein in the mass spectrum. There is no free aspartic acid residue, which can contribute to the negative charge of the protein. The propionic acid groups of the heme moiety and the C-terminal carboxylate residue would contribute to the negative charge of the protein surface. Thus, the expected maximum negative charge state of cytochrome $c$ ions in the negative ESI mass spectrum is -7 (four glutamic acids, C-terminal carboxylate, and two heme propionates). This result thus suggests that only the surface exposed free negative charges are to be considered for the calculation of the number of charge states of the protein in the negative ion mode. The results of charge state analysis by this method, along with ${ }^{\circ}$ those ${ }^{\circ}$ by $^{\circ}$ the ${ }^{\circ}$ RLCT $^{\circ}$ method $^{\circ}[32]^{\circ}$, are $^{\circ}$ given $^{\circ}$ in Table ${ }^{\circ}$.

Calculation of the average molecular mass from the negative ion spectrum of cytochrome $c(\mathrm{M})$ for a molecular ion of the type $[\mathrm{M}-\mathrm{nH}]^{-n}$ (for $n=4$ and 5) gave a molecular mass of $12,358 \pm 2$, which is close to that obtained from the sequence and also from the positive ion spectrum of the protein. This result suggests that in the negative ion electrospray, the protein ions detected by mass spectrometry consist of the free carboxylic acid groups on the protein surface in the negatively charged (deprotonated) form and the exposed free amino groups in the neutral (deprotonated, $R-\mathrm{NH}_{2}$ ) form (see Figure $\left.{ }^{\circ} 1 \mathrm{a}\right)$.

Myoglobin in the negative ion mode. The negative ion ESI mass spectrum of horse myoglobin is given in Figure ${ }^{\circ} 4 \mathrm{~b},{ }^{\circ}$ which ${ }^{\circ}$ shows ${ }^{\circ}$ peaks ${ }^{\circ} a^{\circ}-5^{\circ}$ and $^{\circ}-8^{\circ}$ charge states of the protein ions. The negative ion mass

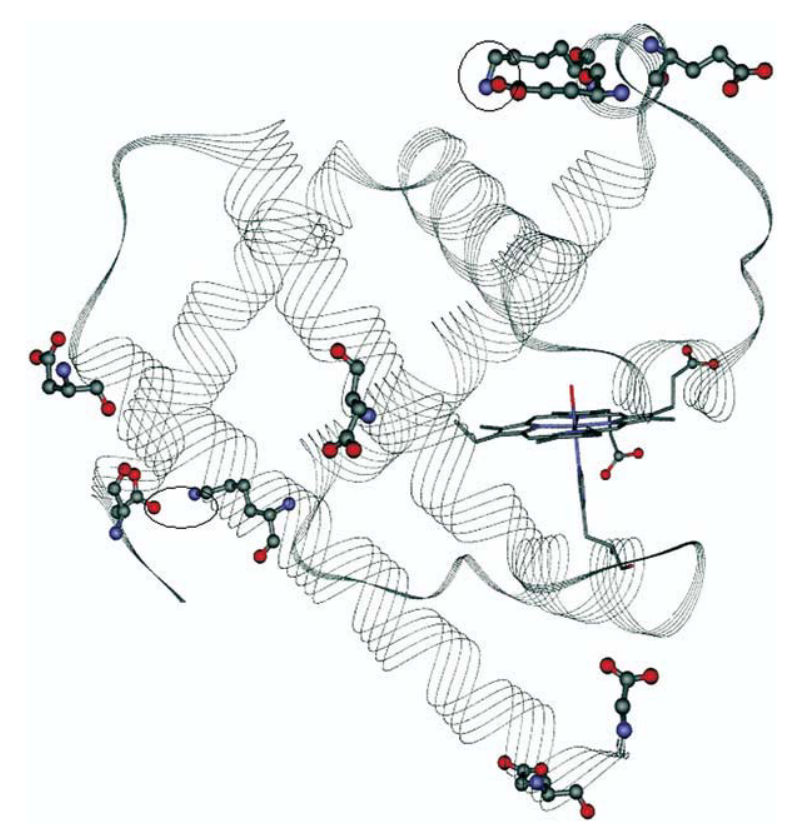

Figure 5. Structure of horse myoglobin (PDB: 1WLA) showing the free exposed acidic residues responsible for the negative charge of the protein ion. Some closely lying residues at the protein surface involved in salt bridges are marked with circles.

spectral signals were two orders weaker compared with the corresponding positive ion spectra. Moreover, the negative ion charge states of myoglobin were almost one order of magnitude weaker compared with those of cytochrome $c$. Analysis of the crystal structure of horse myoglobin (PDB code: 1WLA) shows that one of the eight aspartic acid residues is buried inside the protein. Among the remaining seven surface exposed acidic residues, five aspartic acid residues are involved in salt bridges with the counter cation lying at less than $5 \AA$ from the carboxylate group. Thus, only two exposed aspartic acid residues (D109 and D126) are available to contribute to the negative charge of the protein ion. Analogously, although all of the 13 glutamic acid residues in myoglobin are exposed to the surface, only 2 of them (E54 and E148) are not involved in salt bridge and contribute to the negative charge of the protein in the mass spectrum. Based on this analysis, the expected maximum negative charge in the negative ion mass spectrum of myoglobin would be -7 (two aspartic acids, two glutamic acids, one C-terminal carboxylic acid, and two propionic acid groups of the ${ }^{\circ}$ heme) ${ }^{\circ}$ Figure $^{\circ} 5^{\circ}$ schematically ${ }^{\circ}$ shows ${ }^{\circ}$ the ${ }^{\circ}$ free acidic groups of myoglobin. The results of chargestate analysis by this method along with those by the $\mathrm{RLCT}^{\circ}$ method $^{\circ}[32]^{\circ}$ are $^{\circ}$ given ${ }^{\circ}{ }^{\circ}{ }^{\circ}$ Table $^{\circ} 1$.

Analogous to cytochrome $c$, the negative ion mass spectrum of myoglobin was analyzed considering an ion of the type $[\mathrm{M}-n \mathrm{H}]^{-n}(n=5$ and 6$)$. The molecular mass of the neutral protein $(\mathrm{M})$ was found to be $17,561 \pm 10$, which agrees with that obtained from the sequence and also from the positive ion spectrum of 
the protein. This supports that only the exposed free acidic residues are deprotonated on the protein surface to give the negative ion mass spectrum of the protein.

Lysozyme in the negative ion mode. The negative ion electrospray mass spectrum of chicken lysozyme showed peaks at $-4,-5$, and -6 charge states (data not $^{\circ}$ shown), ${ }^{\circ}$ which ${ }^{\circ}$ agreed $^{\circ}$ with $^{\circ}$ an ${ }^{\circ}$ earlier ${ }^{\circ}$ report ${ }^{\circ}[11]$. Of the seven aspartic acid residues, one is buried and one is involved in salt bridge, leaving five aspartates (D18, D48, D66, D87, and D101) as possible centers to contribute to the negative charge on the protein surface. Among the two glutamates in lysozyme, one is buried and the other one is involved in intramolecular salt-bridge formation. Thus, the total negative charge expected for the folded lysozyme is -6 (five aspartate and C-terminal carboxylate). The maximum negative charge of -6 of lysozyme observed in the negative ion mass spectra of the enzyme agreed well with that determined from the analysis of the crystal structure of the protein. This supports that the charge of the gaseous protein ion in the negative ion mode depends only on the surface exposed free acidic residues and not on the number of positive residues of the protein. The maximum charge states of several proteins calculated from their crystal structures shown ${ }^{\circ}$ in $^{\circ}{ }^{\text {Table }}{ }^{\circ} 1^{\circ}$ agree ${ }^{\circ}$ well $^{\circ}$ with $^{\circ}$ the ${ }^{\circ}$ experimental negative ion mass spectra.

\section{The Number of Alkali Metal Ion Adducts of Proteins and the Maximum Negative Charge State of the Gaseous Protein Ions}

Earlier studies have shown that the presence of potassium or sodium salts often causes broadening of the peaks of the electrospray mass spectrum of a protein [43]. ${ }^{\circ}$ Presence ${ }^{\circ}$ of $^{\circ}$ small $^{\circ}$ concentrations $^{\circ}$ of ${ }^{\circ}$ alkali $^{\circ}$ metal salts, particularly the acetate salts, recently have been shown to give signals corresponding to the formation of adducts $^{\circ}$ of ${ }^{\circ}$ the ${ }^{\circ}$ protein $^{\circ}$ with ${ }^{\circ}$ the ${ }^{\circ}$ alkali $^{\circ}$ ion $^{\circ}\left[28,{ }^{\circ} 43\right]$. Binding of the alkali metal ions to the protein gives rise to the observation of peaks separated by $\left[M_{\mathrm{A}} / n\right]$ in the positive ion mass spectrum of the protein, where $M_{\mathrm{A}}$ is the mass of the alkali metal ion and $n$ is the charge state corresponding to that peak. The adduct peaks were observed along with the parent charge-state peak of the protein and the number of adduct peaks at a given charge state possibly gives an estimate of the number of acidic groups available for binding of the metal ion.

Positive ion ESI mass spectrum of cytochrome $c$ in the ${ }^{\circ}$ presence ${ }^{\circ}$ of $^{\circ}$ potassium $^{\circ}$ acetate $^{\circ}$ given $^{\circ}$ in $^{\circ}$ Figure $^{\circ} 6$ a shows five distinct peaks for the charge state +6 . The same number of adduct peaks were seen for all of the other peaks of the protein. The number of alkali metal bound peaks was found to increase with increasing concentration of $\mathrm{K}^{+}$ion in the desalted protein and shows a maximum of five adduct peaks at protein:

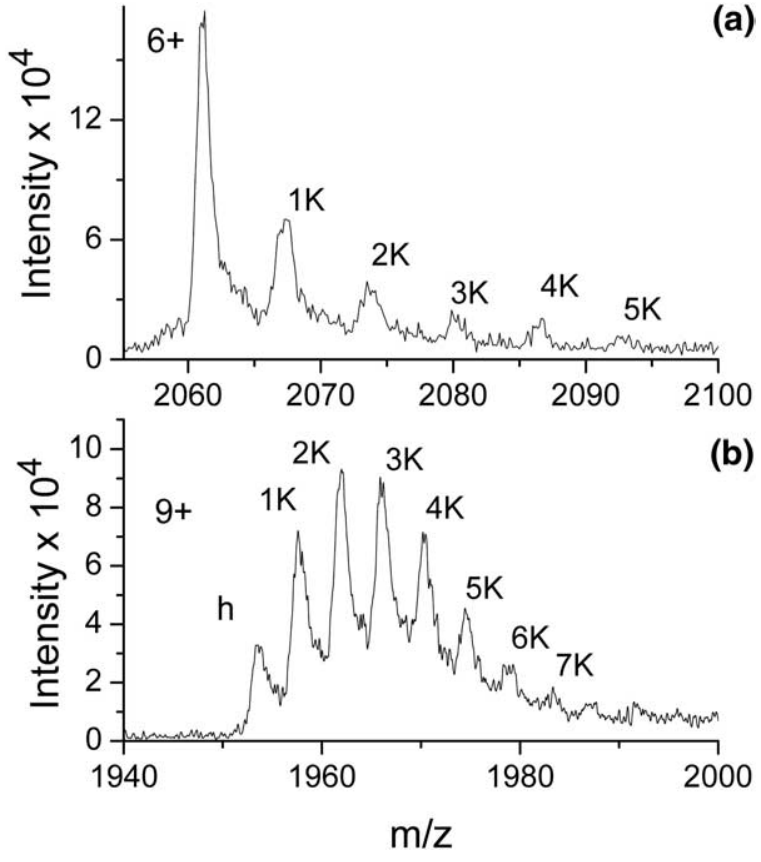

Figure 6. Positive ion ESI mass spectrum of (a) the +6 charge state of cytochrome $c(8 \mu \mathrm{M})$ and $(\mathbf{b})+9$ charge state of myoglobin $(4 \mu \mathrm{M})$ in the presence of potassium acetate $(80 \mu \mathrm{M})$ showing the number of potassium adducts of the protein.

potassium ion approximately 1:5. The number of adduct peaks was unchanged up to 1:10 cytochrome $c$; potassium ion concentration and a further increase in the salt concentration led to complete disappearance of the peaks. Observation of five potassium ion adducts of cytochrome $c$ possibly indicates that there are five carboxylic acid groups at the surface of the protein available for potassium binding. This result agrees with the observation of a maximum -5 charge state of the protein in the negative ion spectrum of cytochrome $c$ as shown ${ }^{\circ}{ }^{\circ}$ Figure 4 a.

Analogously, ESI mass spectrum of myoglobin in the presence of low concentrations of potassium acetate shows distinct peaks corresponding to the formation of seven ${ }^{\circ}$ distinct $^{\circ}$ potassium-adduct ${ }^{\circ}$ peaks ${ }^{\circ}$ (Figure ${ }^{\circ} 6 \mathrm{~b}$ ). ${ }^{\circ}$ Figure $^{\circ} 6 \mathrm{~b}^{\circ}$ shows ${ }^{\circ}$ that ${ }^{\circ}$ there ${ }^{\circ}$ are $^{\circ}$ distinct $^{\circ}$ peaks ${ }^{\circ}$ corresponding to the formation of seven potassium bound adducts of the protein, suggesting that there are seven carboxylic acid groups available at the protein surface for binding ${ }^{\circ}$ to $^{\circ}$ the ${ }^{\circ}$ potassium ${ }^{\circ}$ ion..$^{\circ}$ The $^{\circ}$ results ${ }^{\circ}$ support $^{\circ}$ the observation of a -6 charge state of the holoprotein ions in $^{\circ}$ the $^{\circ}$ negative $^{\circ}$ ion $^{\circ}$ mass $^{\circ}$ spectrum $^{\circ}\left(\text { Figure }^{\circ} 4 \mathrm{~b}\right)^{\circ}$ and agrees with the calculated charge state of -7 for the holoprotein based on the number of isolated acidic groups $^{\circ}$ on $^{\circ}$ the $^{\circ}$ protein $^{\circ}$ surface $^{\circ}\left(\right.$ Table $\left.^{\circ} 1\right) .^{\circ}$ Analogous ${ }^{\circ}$ to that observed in the case of cytochrome $c$, the number of alkali metal adduct peaks of myoglobin was also found to increase on initial addition of low concentrations of $\mathrm{K}^{+}$to the desalted protein. It is, however, important to note that higher concentrations of salt could break the salt bridges involving the acidic residues on the protein surface and may also nonspecifically bind to polar 
groups at the protein surface and thus may give rise to a larger number of alkali metal bound peaks in the mass spectrum of the protein than expected from the number of free negative charges determined from the structure. Weak ${ }^{\circ}$ adduct ${ }^{\circ}$ peaks ${ }^{\circ}$ in $^{\circ}$ Figure $^{\circ} 6 \mathrm{~b}^{\circ}$ corresponding $^{\circ}$ to ${ }^{\circ}$ the formation of nine potassium adducts of myoglobin possibly indicate this. Furthermore, some proteins show specific binding sites for some alkali or alkaline earth $^{\circ}$ metals $^{\circ}$ such $^{\circ}$ as $^{\circ}$ in $^{\circ}$ calmodulin ${ }^{\circ}[7]^{\circ}{ }^{\circ}$ which ${ }^{\circ}$ are important for the structure of the protein. In such cases the metal binding will not directly correlate with the negative charge of the protein surface.

\section{A Model for the Formation of the Charge States of Protein Ions}

The exact mechanism of formation of charged gaseous protein ${ }^{\circ}$ ions $^{\circ}$ still $^{\circ}$ is $^{\circ}$ not $^{\circ}$ unambiguously $^{\circ}$ established $^{\circ}[14$, $\left.31,{ }^{\circ} 37\right] .^{\circ} \mathrm{As}^{\circ}$ par $^{\circ}$ the ${ }^{\circ}$ current $^{\circ}$ understanding ${ }^{\circ}\left[28,{ }^{\circ} 29\right]$, sequential evaporation of the solvent and volatile ions from the charged droplets produced by ESI, along with subsequent coulomb fission, lead to the formation of charged $^{\circ}$ protein $^{\circ}$ molecules $^{\circ}$ in $^{\circ}$ the $^{\circ}$ gaseous $^{\circ}$ phase $^{\circ}[31]$. The charge of the protein in the gaseous state is limited by the Rayleigh limit that basically defines the maximum charge density on the surface of the droplet of the molecular ${ }^{\circ}$ ion $^{\circ}[28]^{\circ}$ and $^{\circ}$ the $^{\circ}$ actual ${ }^{\circ}$ charge $^{\circ}$ on ${ }^{\circ} a^{\circ}$ protein ion thus would be smaller than this limit. There have been several models proposed to interpret the observed charge states of the proteins based on the amino acid sequence $\left[30,{ }^{\circ} 37\right]^{\circ}$ and $^{\circ}$ volume $^{\circ}\left[29,{ }^{\circ} 32\right]^{\circ}{ }^{\circ}$ of $^{\circ}$ the ${ }^{\circ}$ protein.

Calculations of the apparent gas-phase basicity of the protein to give the configuration in which the charges are significantly separated but still located primarily at the most basic sites have been shown to correctly interpret the reported maximum positive charge of a large ${ }^{\circ}$ number ${ }^{\circ}$ of $^{\circ}$ proteins ${ }^{\circ}[30] . .^{\circ}$ This $^{\circ}$ method, $^{\circ}$ however, requires ${ }^{\circ}$ rigorous $^{\circ} \mathrm{computation}^{\circ} \mathrm{of}^{\circ} \mathrm{the}^{\circ} \mathrm{charge} \mathrm{e}^{\circ}$ configurations in the protein.

The soluble proteins in aqueous solution consist of charged/polar groups at the surface that are involved in stabilization of the solvated molecule. The soft ionization method in electrospray possibly does not affect the structure of the protein, and the charged solvent droplets produced by the ESI would contain the proteins in the same conformational state as in the solution. In the process of removal of solvent molecules during the passage of the droplets under vacuum, the solvated sites on the protein surface either form intramolecular hydrogen bonds/ion pairs by interacting with nearby oppositely charged residues on the surface of the protein or abstract proton from the solvent to form free isolated charge centers in the gaseous ion. The charged groups at the core generally are neutralized by a suitable oppositely charged group in the folded protein and thus they would not contribute to the charge state of the folded protein. When positive ions are detected in the mass spectrometer, the potential applied at the ion filter selectively allows detection of positively charged protein ions formed by protonation of the free surface exposed basic residues (making them positively charged) and of the free acidic groups (making them neutral) in the protein surface. The extent of protonation of the basic residues would depend on the apparent gas-phase basicity of that residue in the protein and thus $^{\circ}$ variations $^{\circ}$ in $^{\circ}$ the ${ }^{\circ}$ apparent ${ }^{\circ}$ gas-phase ${ }^{\circ}$ basicity ${ }^{\circ}[30]$ of the basic residues at the surface of the protein would lead to the formation of multiple charged protein ions. The basic residues that form hydrogen bonds at the surface of the gaseous protein molecule would have lower gas-phase basicity compared with those that are isolated (free). The charge-state distribution would then correlate to the protonation equilibria mainly of the free basic residues of the protein. Analogously, the negative ion filter in the mass spectrometer would allow selective detection of negative charges formed by deprotonation of free acidic groups at the protein surface (making them negatively charged) while the basic residues are neutral. This model of formation of multiple charge states of proteins can explain the basis of observation of positive ion mass spectra of a protein with net negative $^{\circ}$ charge $^{\circ}[30]^{\circ}$ and $^{\circ}$ negative ${ }^{\circ}$ ion $^{\circ}$ spectra $^{\circ}$ of $^{\circ}$ a protein with net positive charge, as often observed. Unfolding of the protein would expose the charged residues that are buried in the folded structure; hence, the observed charge state of the protein ions are higher in the unfolded protein compared with the folded protein.

The charge states in the mass spectra of the protein, however, would depend on the experimental conditions and the foregoing model would apply only if soft ionization conditions are maintained. Protonation of the basic residues on the protein surface by excess ion flux can cause unfolding of the protein, analogous to that observed at low $\mathrm{pH}$ in solution. It has recently been shown ${ }^{\circ}$ that ${ }^{\circ}\left[39,{ }^{\circ} 52\right]^{\circ}$ instrumental $^{\circ}$ parameters $^{\circ}$ such $^{\circ}$ as spray voltage, gas flow, capillary temperature, etc., can affect the charge-state distribution of protein ions because of unfolding. The present model based on the crystal structure of the protein would apply in the soft ionization domain and the ESI mass spectral parameters are optimized so that the spectrum is independent of small variations in the experimental conditions.

\section{Conclusions}

The soft ionization by electrospray technique possibly retains the tertiary structure of most proteins in the gaseous phase and the observation of multiple charge states of the folded protein ions in the electrospray mass spectrum thus depends on the tertiary structure of the protein $[10] .{ }^{\circ} \mathrm{We}^{\circ}$ have ${ }^{\circ}$ analyzed ${ }^{\circ}$ the $^{\circ}$ crystal $^{\circ}$ structure ${ }^{\circ}$ of cytochrome $c$, myoglobin, lysozyme, bovine carbonic anhydrase II, and several other proteins of different molecular weight and surface charge to identify the residues responsible for the charge state of these proteins in the gaseous phase. The crystal structures of 
these proteins show that some of the surface exposed basic and acidic groups are involved in hydrogenbonding or salt-bridge interactions. These interactions would potentially affect the charge density at these centers and thereby decrease their ability to contribute to the charge state of the protein. Thus, the surface exposed basic or acidic residues that are not involved in any such interaction would only contribute to the charge state of the protein ion. These residues are identified as the "free residues" in the crystal structure of the protein. The maximum charge state of the gaseous protein ion in the folded form thus would be equal to the number of the free basic or free acidic residues respectively in the positive or negative ion spectrum of the protein. The charge state of the folded protein shows a monomodal distribution and the actual charge states would depend on the relative basicity or acidity of these free residues on the protein surface.

The analyses of the positive and negative ion spectra were performed to determine the average molecular weight of the protein. These analyses suggested that only the protonated free basic residues at the protein surface are responsible for the positive charge of the protein ion and deprotonation of the free acidic groups at the protein surface gives rise to the negative protein ions. The observation of the potassium adduct peaks in the presence of low concentrations of the potassium acetate was correlated with the maximum negative charge or the number of free acidic residues at the protein surface.

These studies show that consideration of only the free basic groups at the protein surface is sufficient to interpret the positive ion mass spectrum of a protein. Analogously, only the free surface exposed acidic groups responsible for the negative charge of the protein ion detected by negative ion mass spectrum.

\section{Acknowledgments}

Authors thank Mr. Bharat T. Kansara for his help. This work was supported by the Tata Institute of Fundamental Research.

\section{References}

1. Cristoni, S.; Bernardi, L. R. Development of New Methodologies for the Mass Spectrometry Study of Bioorganic Macromolecules. Mass. Spectrom. Rev. 2003, 22, 369-406.

2. Loo, J. A. Studying Noncovalent Protein Complexes by Electrospray Ionization Mass Spectrometry. Mass. Spectrom. Rev. 1997, 16, 1-23.

3. Julian, R. R.; Hodyss, R.; Beauchamp, J. L. Salt Bridge Stabilization of Charged Zwitterionic Arginine Aggregates in the Gas Phase. J. Am. Chem. Soc. 2001, 123, 3577-3583.

4. Bouchoux, G.; Salpin, J. Y. Gas-Phase Basicity of Glycine, Alanine, Proline, Serine, Lysine, Histidine, and Some of Their Peptides by the Thermokinetic Method. Eur. J Mass. Spectrom. (Chichester Eng.) 2003, 9, 391-402.

5. Burkitt, W. I.; Derrick, P. J.; Lafitte, D.; Bronstein, I. ProteinLigand and Protein-Protein Interactions Studied by Electrospray Ionization and Mass Spectrometry. Biochem. Soc. Trans. 2003, 31, 985-989.
6. Wells, J. M.; Chrisman, P. A.; McLuckey, S. A. Formation and Characterization of Protein-Protein Complexes In Vacuo. J. Am. Chem. Soc. 2003, 125, 7238-7249.

7. Lafitte, D.; Heck, A. J.; Hill, T. J.; Jumel, K.; Harding, S. E.; Derrick, P. J. Evidence of Noncovalent Dimerization of Calmodulin. Eur. J. Biochem. 1999, 261, 337-344.

8. Daneshfar, R.; Kitova, E. N.; Klassen, J. S. Determination of Protein-Ligand Association Thermochemistry Using VariableTemperature Nanoelectrospray Mass Spectrometry. J. Am. Chem. Soc. 2004, 126, 4786-4787.

9. Grandori, R. Detecting Equilibrium Cytochrome $c$ Folding Intermediates by Electrospray Ionisation Mass Spectrometry: Two Partially Folded Forms Populate the Molten-Globule State. Protein Sci. 2002, 11, 453-458.

10. Konermann, L.; Douglas, D. J. Acid-Induced Unfolding of Cytochrome $c$ at Different Methanol Concentrations: Electrospray Ionization Mass Spectrometry Specifically Monitors Changes in the Tertiary Structure. Biochemistry 1997, 36, $12296-12302$.

11. Konermann, L.; Douglas, D. J. Unfolding of Proteins Monitored by Electrospray Ionization Mass Spectrometry: A Comparison of Positive and Negative Ion Modes. J. Am. Soc. Mass. Spectrom. 1998, 9, 1248-1254.

12. Konermann, L.; Simmons, D. A. Protein-Folding Kinetics and Mechanisms Studied by Pulse-Labeling and Mass Spectrometry. Mass. Spectrom. Rev. 2003, 22, 1-26.

13. Simmons, D. A.; Dunn, S. D.; Konermann, L. Conformational Dynamics of Partially Denatured Myoglobin Studied by Time-Resolved Electrospray Mass Spectrometry with Online Hydrogen-Deuterium Exchange. Biochemistry 2003, 42, 58965905.

14. Iavarone, A. T.; Williams, E. R. Mechanism of Charging and Supercharging Molecules in Electrospray Ionization. J. Am. Chem. Soc. 2003, 125, 2319-2327.

15. Babu, K. R.; Douglas, D. J. Methanol-Induced Conformations of Myoglobin at pH 4.0. Biochemistry 2000, 39, 14702-14710.

16. Kitova, E. N.; Wang, W.; Bundle, D. R.; Klassen, J. S. Retention of Bioactive Ligand Conformation in a Gaseous ProteinTrisaccharide Complex. J. Am. Chem. Soc. 2002, 124, 1398013981.

17. Zhang, S.; Van Pelt, C. K.; Wilson, D. B. Quantitative Determination of Noncovalent Binding Interactions Using Automated Nanoelectrospray Mass Spectrometry. Anal. Chem. 2003, 75, 3010-3018.

18. Wendt, S.; McCombie, G.; Daniel, J.; Kienhofer, A.; Hilvert, D.; Zenobi, R. Quantitative Evaluation of Noncovalent Chorismate Mutase-Inhibitor Binding by ESI-MS. J. Am. Soc. Mass. Spectrom. 2003, 14, 1470-1476.

19. Tjernberg, A.; Carno, S.; Oliv, F.; Benkestock, K.; Edlund, P. O.; Griffiths, W. J.; Hallen, D. Determination of Dissociation Constants for Protein-Ligand Complexes by Electrospray Ionization Mass Spectrometry. Anal. Chem. 2004, 76, 4325-4331.

20. Hagan, N.; Fabris, D. Direct Mass Spectrometric Determination of the Stoichiometry and Binding Affinity of the Complexes Between Nucleocapsid Protein and RNA Stem-Loop Hairpins of the HIV-1 Psi-Recognition Element. Biochemistry 2003, 42, 10736-10745.

21. Kapur, A.; Beck, J. L.; Brown, S. E.; Dixon, N. E.; Sheil, M. M. Use of Electrospray Ionization Mass Spectrometry to Study Binding Interactions Between a Replication Terminator Protein and DNA. Protein Sci. 2002, 11, 147-157.

22. Kempen, E. C.; Brodbelt, J. S. A Method for the Determination of Binding Constants by Electrospray Ionization Mass Spectrometry. Anal. Chem. 2000, 72, 5411-5416.

23. Breuker, K.; Oh, H.; Horn, D. M.; Cerda, B. A.; McLafferty, F. W. Detailed Unfolding and Folding of Gaseous Ubiquitin 
Ions Characterized by Electron Capture Dissociation. J. Am. Chem. Soc. 2002, 124, 6407-6420.

24. Loo, J. A. Electrospray Ionization Mass Spectrometry: A Technology for Studying Noncovalent Macromolecular Complexes. Int. J. of. Mass. Spectrom. 2000, 200, 175-186.

25. Gologan, B.; Takats, Z.; Alvarez, J.; Wiseman, J. M.; Talaty, N.; Ouyang, Z.; Cooks, R. G. Ion Soft-Landing into Liquids: Protein Identification, separation, and Purification with Retention of Biological Activity. J. Am. Soc. Mass Spectrom. 2004, 15, 1874-1884.

26. Gross, D. S.; Schnier, P. D.; Rodriguez-Cruz, S. E.; Fagerquist, C. K.; Williams, E. R. Conformations and Folding of Lysozyme Ions In Vacuo. Proc. Natl. Acad. Sci. U.S.A. 1996, 93, 3143-3148.

27. Oh, H.; Breuker, K.; Sze, S. K.; Ge, Y.; Carpenter, B. K.; McLafferty, F. W. Secondary and Tertiary Structures of Gaseous Protein Ions Characterized by Electron Capture Dissociation Mass Spectrometry and Photofragment Spectroscopy. Proc. Natl. Acad. Sci. U.S.A. 2002, 99, 15863-15868.

28. Felitsyn, N.; Peschke, M.; Kebarle, P. Origin and Number of Charges Observed on Multiply Protonated Native Proteins Produced by ESI. Int. J. Mass Spectrom. 2002, 219, 39-62.

29. Fernandez de la Mora, J. Electrospray Ionization of Large Multiply Charged Species Proceeds via Dole's Charged Residue Mechanism. Anal. Chim. Acta. 2000, 406, 93-104.

30. Schnier, P. D.; Gross, D. S.; Williams, E. R. On the Maximum Charge State and Proton Transfer Reactivity of Peptide and Protein Ions Formed by Electrospray Ionization. J. Am. Soc. Mass Spectrom. 1995, 6, 1086-1097.

31. Kebarle, P. A Brief Overview of the Present Status of the Mechanisms Involved in Electrospray Mass Spectrometry. J. Mass. Spectrom. 2000, 35, 804-817.

32. Nesatyy, V. J.; Suter, M. J. -F. On the Conformation-Dependent Neutralization Theory and Charging of Individual Proteins and Their Non-Covalent Complexes in the Gas Phase. J. Mass Spectrom. 2004, 39, 93-97.

33. Jurchen, J. C.; Cooper, R. E.; Williams, E. R. The role of acidic residues and of sodium ion adduction on the gas-phase H/D exchange of peptides and peptide dimers. J Am. Soc. Mass. Spectrom. 2003, 14(12), 1477-87.

34. Peschke, M.; Blades, A.; Kebarle, P. Charged States of Proteins. Reactions of Doubly Protonated Alkyldiamines with $\mathrm{NH}(3)$ : Solvation or Deprotonation. Extension of Two Proton Cases to Multiply Protonated Globular Proteins Observed in the Gas Phase. J. Am. Chem. Soc. 2002, 124, 11519-11530.

35. Williams, E. R. Proton Transfer Reactivity of Large Multiply Charged ions. J. Mass Spectrom. 1996, 31, 831-842.

36. Blades, A.; Peschke, M.; Verkerk, U.; Kebarle, P. Rates of Proton Transfer from Carboxylic Acids to Dianions, $\mathrm{CO} 2(\mathrm{CH} 2) \mathrm{pCO} 22-$, and Their Significance to Observed Negative Charge States of Proteins in the Gas Phase. J. Phys. Chem. A 2002, 106, 10037-10042.

37. Grandori, R. Origin of the Conformation Dependence of Protein Charge-State Distributions in Electrospray Ionization Mass Spectrometry. J. Mass Spectrom. 2003, 38, 11-15.

38. Verkerk, U. H.; Peschke, M.; Kebarle, P. Effect of Buffer Cations and of $\mathrm{H} 3 \mathrm{O}+$ on the Charge States of Native Proteins. Significance to Determinations of Stability Constants of Protein Complexes. J. Mass Spectrom. 2003, 38, 618-631.

39. Samalikova, M.; Matecko, I.; Muller, N.; Grandori, R. Interpreting Conformational Effects in Protein Nano-ESI-MS Spectra. Anal. Bioanal. Chem. 2004, 378, 1112-1123.

40. Rodriguez, R.; Chinea, G.; Lopez, N.; Pons, T.; Vriend, G. Homology Modeling, Model, and Software Evaluation: Three Related Resources 1998, 14, 523-528.
41. Vriend, G. WHAT IF: A molecular modeling and drug design program. J. Mol. Graph. 1990, 8, 52-56.

42. Kumar, S.; Nussinov, R. Relationship Between Ion Pair Geometries and Electrostatic Strengths in Proteins. Biophys. J. 2002, $83,1595-1612$

43. Iavarone, A. T.; Udekwu, O. A.; Williams, E. R. Buffer Loading for Counteracting Metal Salt-Induced Signal Suppression in Electrospray Ionization. Anal. Chem. 2004, 76, 3944-3950.

44. Chattopadhyay, K.; Mazumdar, S. Stabilization of Partially Folded States of Cytochrome $c$ in Aqueous Surfactant: Effects of Ionic and Hydrophobic Interactions. Biochemistry 2003, 42, 14606-14613.

45. Zhang, Z.; Marshall, A. G. A Universal Algorithm for Fast and Automated Charge State Deconvolution of Electrospray MassTo-Charge Ratio Spectra. J. Am. Soc. Mass Spectrom. 1998, 9, 225-233.

46. Stephenson, J. L. Jr.; McLuckey, S. A. Ion/Ion Proton Transfer Reactions for Protein Mixture Analysis. Anal. Chem. 1996, 68, 4026-4032.

47. Samalikova, M.; Grandori, R. Role of Opposite Charges in Protein Electrospray Ionization Mass Spectrometry. J. Mass Spectrom. 2003, 38, 941-947.

48. Hautreux, M.; Hue, N.; Du Fou. de Kerdaniel, A.; Zahir, A.; Malec, V.; Laprevote, O. Under Non-Denaturing Solvent Conditions, the Mean Charge State of a Multiply Charged Protein Ion Formed by Electrospray Is Linearly Correlated with the Macromolecular Surface. Int. J. Mass Spectrom. 2004, 231, 131-137.

49. Ray, S. S.; Singh, S. K.; Balaram, P. An Electrospray Ionization Mass Spectrometry Investigation of 1-Anilino-8-NaphthaleneSulfonate (ANS) Binding to Proteins. J. Am. Soc. Mass Spectrom. 2001, 12, 428-438.

50. Iavarone, A. T.; Williams, E. R. Supercharging in Electrospray Ionization: Effects on Signal and Charge. Int. J. Mass Spectrom. 2002, 219, 63-72.

51. Sogbein, O. O.; Simmons, D. A.; Konermann, L. Effects of $\mathrm{pH}$ on the Kinetic Reaction Mechanism of Myoglobin Unfolding Studied by Time-Resolved Electrospray Ionization Mass Spectrometry. J. Am. Soc. Mass Spectrom. 2000, 11, 312-319.

52. Samalikova, M., Grandori, R. Protein Charge-State Distributions in Electrospray-Ionization Mass Spectrometry Do Not Appear to be Limited by the Surface Tension of the Solvent. J. Am. Chem. Soc. 2003, 125, 13352-13353.

53. Robinson, C. V.; Chung, E. W.; Kragelund, B. B.; Knudsen, J.; Aplin, R. T.; Poulsen, F. M.; Dobson, C. M. Probing the Nature of Noncovalent Interactions by Mass Spectrometry. A Study of Protein-CoA Ligand Binding and Assembly. J. Am. Chem. Soc. 1996, 118, 8646-8653.

54. Loo, J. A.; Hu, P.; McConnell, P.; Muller, W. T.; K., S. T.; Thanabal, V. A Study of Src SH2 Domain Protein-Phosphopetide Binding Interactions by Electrospray Ionisation Mass Spectrometry. J. Am. Soc. Mass Spectrom. 1997, 8, 234-243.

55. Potier, N.; Donald, L. J.; Chernushevich, I.; Ayed, A.; Ens, W.; Arrowsmith, C. H.; Standing, K. G.; Duckworth, H. W. Study of a Noncovalent trp Repressor: DNA Operator Complex by Electrospray Ionization Time-Of-Flight Mass Spectrometry. Protein Sci. 1998, 7, 1388-1395.

56. Babu, K. R.; Moradian, A.; Douglas, D. J. The MethanolInduced Conformational Transitions of Beta-Lactoglobulin, Cytochrome $c$, and Ubiquitin at Low pH: A Study by Electrospray Ionization Mass Spectrometry. J. Am. Soc. Mass Spectrom. 2001, 12, 317-328.

57. Gumerov, D. R.; Kaltashov, I. A. Dynamics of Iron Release from Transferrin $\mathrm{N}$-lobe Studied by Electrospray Ionization Mass Spectrometry. Anal. Chem. 2001, 73, 2565-2570. 